\title{
An unusual presentation of hydatid cyst in anterior abdominal wall
} Srivastava $\mathrm{P}^{1}$, Gangopadhyay $\mathrm{AN}^{2}$, Upadhyaya $\mathrm{VD}^{3}$, Sharma $\mathrm{SP}^{4}$, Jaiman $\mathrm{R}^{5}$

${ }^{1}$ Senior Resident, ${ }^{2}$ Professor, ${ }^{3}$ Research Associate, ${ }^{4}$ Reader, Department of Paediatric Surgery, IMS, BHU, Varanasi, India, ${ }^{5}$ Lecturer, General Surgery, S N Medical College, Agra, India

\begin{abstract}
Hydatid disease is a parasitic infestation caused by the larval form of the cestode worm Echinococcus. The most commonly encountered form of the disease is visceral hydatid cyst caused by Echinococcus granulosus or dog tapeworm. Muscular involvement has been reported in only $3-4 \%$ cases. We are reporting this case because of its rarity, difficulty to diagnose clinically, dramatic response to medical treatment and to alert the reader of this rare infestation so that open biopsy will be avoided.
\end{abstract}

Key words: Hydatid cyst, parietal wall, medical treatment

$\mathrm{H}$ ydatid disease is a parasitic infestation by a tapeworm of the genus Echinococcus. Human echinococcosis is a zoonotic infection caused by the tapeworm of the genus Echinococcus. Dog is the primary host in echinococcal infestation while the intermediate hosts are sheep, cattle, horses, and occasionally man. For this reason, hydatid disease has its highest incidence in sheep and cattle-rearing regions, such as the Mediterranean countries, the Middle East, the southern part of South America, Iceland, Australia, New Zealand, and southern parts of Africa ${ }^{1,2}$. In hydatid disease, muscles, apart from myocardium, are generally only involved as a result of spread from hepatic or pulmonary foci. Primary hydatidosis of skeletal muscle is therefore rare, with reported prevalence of $0.5-4.7 \% 0^{3,4}$ . It has been hypothesized that the presence of lactic acid in the muscles does not allow the larvae to grow into cysts $^{5}$. Nevertheless, some cases of primary muscular hydatidosis at various sites had been reported, i.e. thoracic wall ${ }^{6}$, sartorius ${ }^{7}$, biceps brachii ${ }^{5}$, supraspinatus ${ }^{8}$, gluteus ${ }^{9}$, and soleus muscles ${ }^{10}$, but involvement of abdominal parietal wall had not been reported till now. Extrahepatic and extrathoracic involvement of the hydatid disease including bones, heart, spine, pelvicperianal region, muscles, subcutaneous space, adrenal, ovaries, retroperitoneum, breast, and cranium have been reported. The recommended treatment of Echinococcus is complete excision of the cyst lining and thorough irrigation of the cyst cavity with hypertonic saline to decrease the risk of recurrence. In an endemic region, where there is familiarity with this condition, the occurrence of hydatid disease in common sites makes for a straightforward diagnosis, but when it occurs in unusual sites (and in uncommon regions), the diagnosis may be difficult not only due to a low prevalence and unusual location, but also because complicated cysts may resemble solid or complex lesions such as soft tissue tumors ${ }^{11}$. We are reporting this case because of its rarity, difficulty in clinical diagnosis, dramatic response to medical treatment and to alert the reader of this rare infestation so that open biopsy will be avoided.

\section{Case report}

A 14 year male in our hospital presented with swelling in right anterior abdominal wall since three months. There was no history of fever, vomiting pain, trauma, weight loss, irradiation and other disorder. On physical examination $10 \times 6 \mathrm{~cm}$ parietal swelling in right lower abdominal wall (at the junction of lateral $1 / 3^{\text {rd }}$ and medial $2 / 3^{\text {rd }}$ of the line joining umbilicus to anterior superior iliac spine) which was non tender, firm in consistency and skin overlying swelling was normal. There was no cough impulse in swelling and it was not reducible. [Figure-1]. On hematological examination, hemoglobin was $10.0 \mathrm{gm} \%$ total leucocytes count was 7500/cumm (neutrophil 65, lymphocyte 32 \& eosinophil 3). Erythrocyte sedimentation rate (ESR) was $10 \mathrm{~mm}$. X-ray abdomen and chest was normal. On ultrasound examination a well defined spindle shaped anechoic lesion of size $11.2 \times 3.5 \mathrm{~cm}$ was seen in muscle of right lower abdominal wall (in right iliac fossa). The lesion had multiple daughter cysts [Figure-2]. The patient was subjected to plasma IgG anti-echinococcal antibody titers which was $14.27 \mathrm{U} / \mathrm{mL}$ at the time of presentation.

\section{Correspondence}

Dr. Punit Srivastava

Department of Pediatric Surgery

IMS, BHU, Varanasi, India

E-mail: contact2ps@rediffmail.com 
The patients were reluctant to admission and operation, so the patient was managed conservatively (Albendazole - $50 \mathrm{mg} / \mathrm{kg} /$ day). The patients came after 14 week with dramatic disappearance of the lesion [figure-3]. On repeat ultrasound examination the lesion had no daughter

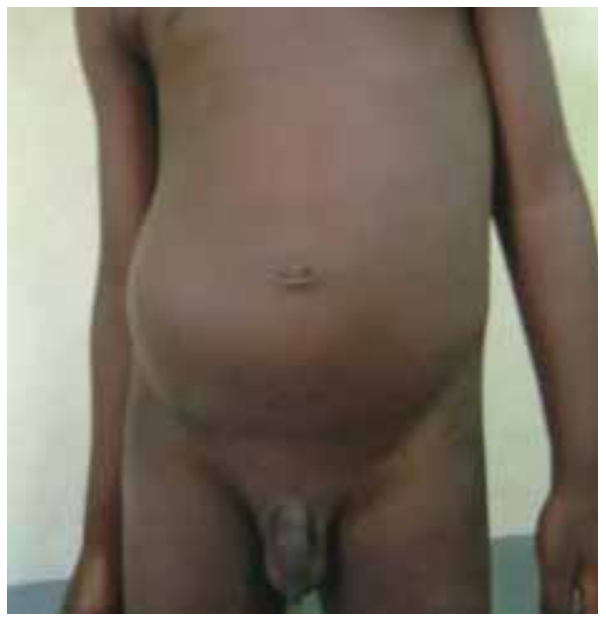

Fig 1: Abdominal wall swelling in right lower abdomen

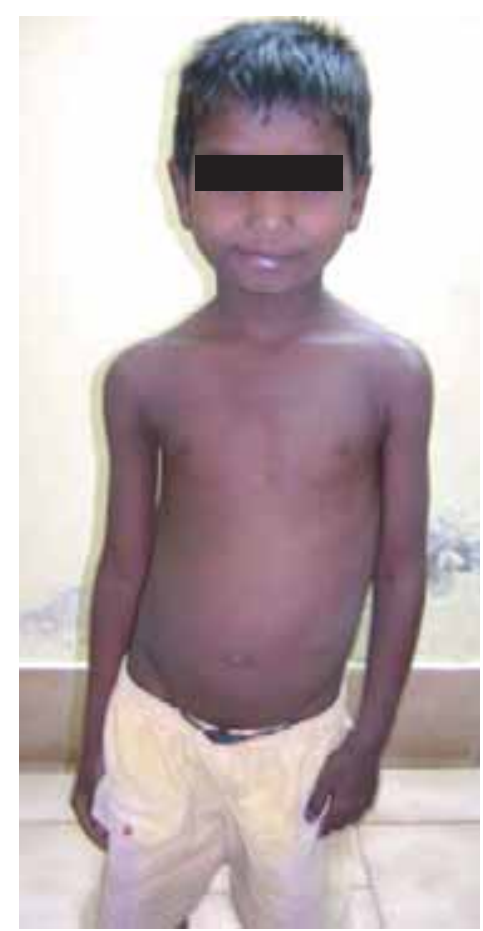

Fig 3: The patient after medical treatment cyst and lesion had almost disappeared [figure-4]. The repeat serological tests showed a decrease in the $\mathrm{IgG}$ anti-echinococcal antibody titres to $0.69 \mathrm{U} / \mathrm{mL}$. He was under regular follow up for two years and is now asymptomatic.

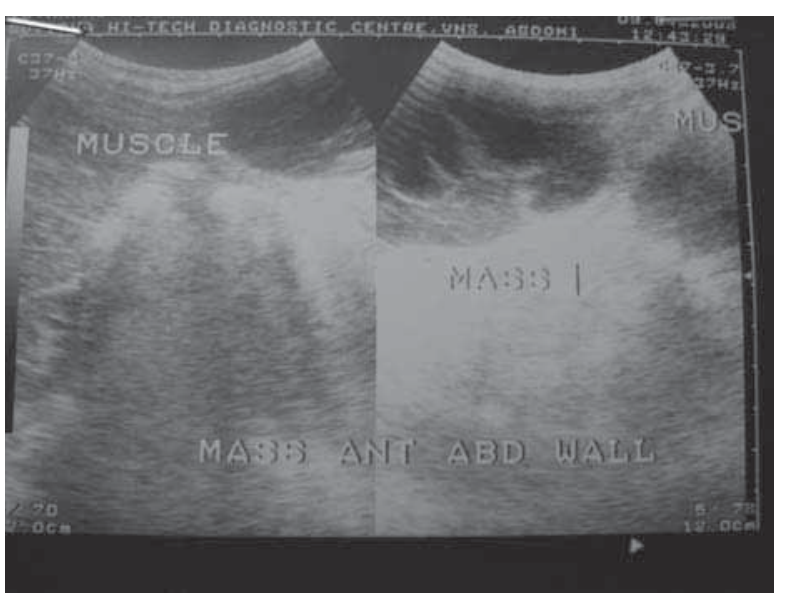

Fig 2: USG showing multiple daughter cysts in the abdominal wall

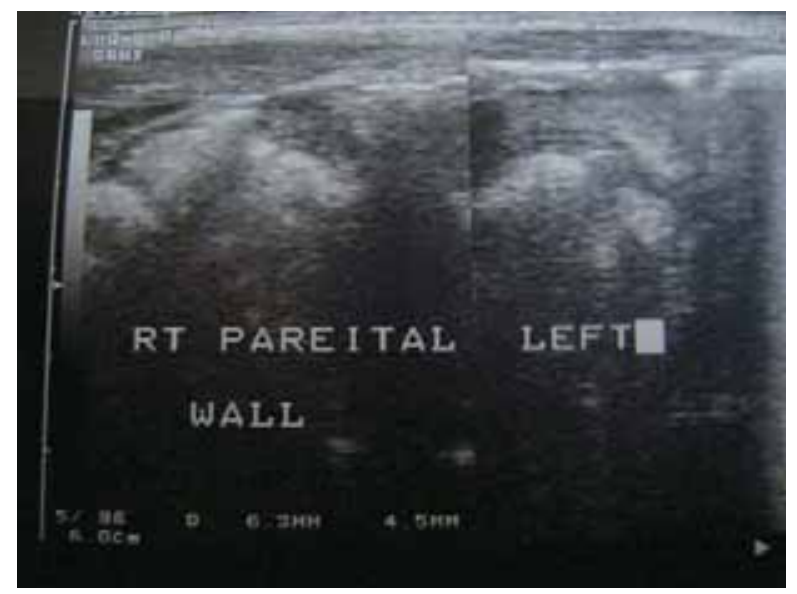

Fig 4: USG showing disappearance of lesion 


\section{Discussion}

In humans the infestation is usually localized in the liver and lungs, and rarely involves the brain, heart, bone, or other organs ${ }^{12}$. However, a review of the English medical literature also revealed cases involving the muscles of the chest wall $^{6}$, sartorius ${ }^{7}$ and biceps brachii ${ }^{5}$, supraspinatus ${ }^{8}$, and gluteus ${ }^{9}$, although it has been suggested that muscle provides a poor environment for the parasite because of the presence of lactic acid ${ }^{5}$. The clinical manifestation of the disease is formed by localization and pressure effect of the slowly growing cyst in the infected organ. Preoperative ultrasonography ${ }^{13}$ and CT (Computerized tomography scan) are helpful in visualizing the cyst as well as daughter cysts. Fine needle aspiration biopsy is not recommended, since there is the risk of spillage and allergic reactions ${ }^{11}$. In present case, hydatidosis of parietal wall was diagnosed by ultrasonographic finding and was confirmed by plasma IgG anti-echinococcal antibody titers. The definitive treatment for hydatid cyst is surgery ${ }^{13}$, however, rupture of the cyst leading to spillage and contamination of the surrounding tissues should be avoided ${ }^{8}$. Medical treatment consists of Mebendazole and Albendazole especially for disseminated, inaccessible hydatidosis, and for patients who do not favor the morbidity of an operative process. Available data on the effects of medical treatment for recurrence is still lacking but there are few reports which advocate medical treatment ${ }^{14,15}$. In present, cases the patient was not willing for operation so we started medical treatment.

\section{Conclusion}

The diagnosis of hydatidosis should be considered in cases of a symptomatic swelling in musculoskeletal system without history of trauma and irradiation when patients belong to endemic area to avoid fineneedle biopsy and the consequences of spillage of cyst contents.

\section{References}

1. EckertJ,DeplazesP. Biological,Epidemiological and Clinical Aspects of Echinococcosis, a Zoonosis of Increasing Concern. Clin Microbiol Rev 2004;17(1):107-35.

2. Garippa G. Updates on cystic echinococcosis (CE) in Italy. Parassitologia 2006;48:57-9.

3. Merkle EM, Schulte M, Vogel J, Tomczak R, Rieber A, Kern P, et al. Musculoskeletal involvement in cystic echinococcosis: report of eight cases and review of the literature. Am J Roentgenol 1997;168:1531-4.
4. Tacal T, Altinok D, Yildiz YT, Altinok G. Coexistence of intramuscular hydatid cyst and tape worm. Am J Rotenjol 2000;174:575-6.

5. Duncan GJ, Tooke SM. Echinococcus infestation of the biceps brachii. A case report. Clin Orthop Relat Res. 1990;261:247-50.

6. Alvarez-Sala R, Caballero P. Echinococcus cyst as a cause of chest wall tumor. Ann Thorac Surg 1987;43:689-90.

7. Rask MR, Lattig GJ. Primary intramuscular hydatidosis of the sartorius. J Bone Joint Surg Am 1970;52:582-4.

8. Tatari H, Baran O, Sanlidag T, Gore O, Ak D, Manisali M, et.al. Primary intramuscular hydatidosis of supraspinatus muscle. Arch Orthop Trauma Surg. 2001;121:93-4.

9. Combalia A, Sastre-Solsona S. Hydatid cyst of gluteus muscle. Two cases. Review of the literature. Joint Bone Spine 2005;72(5):430-2.

10. Togrul E, Kalaci A, Sarpel Y, Koltay IS, Ozbarlas S. What's your diagnosis? Solitary hydatid cyst of the soleus muscle. Ann Saudi Med 2004;24(288):307-9.

11. Tacal T, Altinok D, Yildiz YT, Altinok G. Coexistence of intramuscular hydatid cyst and tapeworm. Am J Roentgenol 2000;174:575-6.

12. Little JM. Hydatid disease of Royal Albert Hospital, 1964- 1974. Med. J. Awst. 1976;1:903.

13. El Malki HO, El Mejdoubi Y, Bouslami B, Mohsine R, Ifrine L, Belkouchi A. Hydatid cyst of the psoas muscle. Sante 2007 Jul-Sep; 17(3):177-9.

14. Zambelli S, Carnevale G, Prata M, Barbero E, Mastinu A, Vergara E. Hydatidosis of the psoas muscle. Description of a case and review of the literature. Arch Esp Urol.1991 Sep;44(7):864-6.

15. Michail OP, Georgiou C, Michail PO, Felekouras E, Karavokyros I, Marinos G et al. Disappearance of recurrent intra-abdominal extrahepatic hydatid cyst following oral albendazole administration. West Indian Med J. 2007 Sep;56(4):372-5. 